\title{
Breast Cancer Risk Assessment: Evaluation of Screening Tools for Genetics Referral
}

Maren Lothyan Zaro

Brigham Young University

Follow this and additional works at: https://scholarsarchive.byu.edu/etd

Part of the Nursing Commons

\section{BYU ScholarsArchive Citation}

Zaro, Maren Lothyan, "Breast Cancer Risk Assessment: Evaluation of Screening Tools for Genetics Referral" (2016). Theses and Dissertations. 8824.

https://scholarsarchive.byu.edu/etd/8824

This Thesis is brought to you for free and open access by BYU ScholarsArchive. It has been accepted for inclusion in Theses and Dissertations by an authorized administrator of BYU ScholarsArchive. For more information, please contact scholarsarchive@byu.edu, ellen_amatangelo@byu.edu. 


\title{
Breast Cancer Risk Assessment:
}

Evaluation of Screening Tools for Genetics Referral

\author{
Maren Lothyan Zaro
}

A thesis submitted to the faculty of

Brigham Young University

in partial fulfillment of the requirements for the degree of

Master of Science

Deborah O. Himes, Chair

Mary Williams

Donna Freeborn

College of Nursing

Brigham Young University

June 2016

Copyright (C) 2016 Maren Lothyan Zaro

All Rights Reserved 


\author{
ABSTRACT \\ Breast Cancer Risk Assessment: \\ Evaluation of Screening Tools for Genetics Referral \\ Maren Lothyan Zaro \\ College of Nursing, BYU \\ Master of Science
}

Purpose: This study assessed effectiveness of five tools recommended by the US Preventive Services Task Force (USPSTF), designed to help primary care clinicians determine which unaffected patients to refer to genetics specialists for breast cancer risk assessment based on concerning family history.

Design: This descriptive secondary analysis included 85 women aged 40-74. All participants had a first-degree female relative previously diagnosed with breast cancer who also had uninformative negative $B R C A 1 / 2$ tests.

Methods: Each pedigree was evaluated using the five tools including the Family History Screen-7 (FHS-7), Pedigree Assessment Tool (PAT), Manchester Scoring System, Referral Screening Tool (RST), and Ontario-Family History Assessment Tool (OntarioFHAT). All five tools were applied to each study participant. Sensitivity, specificity, positive predictive value, and negative predictive value were calculated to describe each tool's ability to identify women with elevated risk as calculated by the Claus model. Receiver operating curves (ROC) were also plotted. Differences between areas under the curve (AUCs) for all possible pairs of tools were estimated through logistic regression to assess for differences in tool performance.

Results: Claus calculations identified 14 women out of 85 whose lifetime risk of breast cancer was elevated at $\geq 15 \%$. Only two tools, the Ontario-FHAT and FHS-7, identified all 14 women with elevated risk, a sensitivity of $100 \%$. The FHS-7 tool flagged all 85 participants, meaning its specificity was zero. The Ontario-FHAT flagged 59 participants as needing referral (specificity $36.2 \%$ ) and had a negative predictive value (NPV) of $100 \%$, indicating that if a woman was not found to need a referral to a genetics professional, it is likely she did not have an elevated lifetime risk of developing breast cancer. AUC values were not significantly different between tools (all $p$ values $>.05$ ), and thus were not helpful in discriminating between the tools.

Conclusion: In this population, the Ontario-FHAT out-performed other tools in terms of sensitivity and negative predictive value; however, low specificity and positive predictive value must be balanced against these findings. Thus, the Ontario-FHAT can help determine which women would benefit from referral to a genetics specialist.

Keywords: risk assessment, medical management, breast cancer screening, BRCA1/2, USPSTF, hereditary breast cancer, FHAT, FHS-7, PAT, Manchester, RST 


\section{ACKNOWLEDGEMENTS}

This thesis would not be complete without my grateful acknowledgement to my committee, especially my chair, Deborah Himes, and Mary Williams and Donna Freeborn, who have worked many hours honing this paper. Thank you all so much for your guidance and good humor. 


\section{TABLE OF CONTENTS}

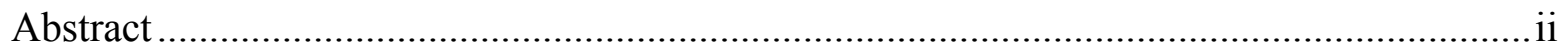

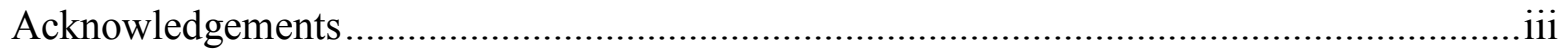

Table of Contents .............................................................................................................

List of Tables and Figures....................................................................................... vi

Manuscript: Breast Cancer Risk Assessment: Evaluation of

Screening Tools for Genetics Referral.......................................................................

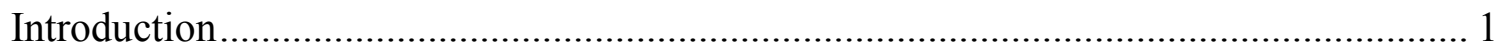

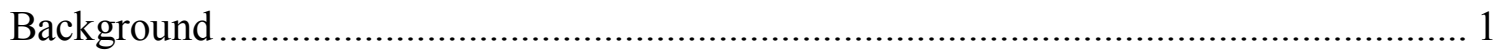

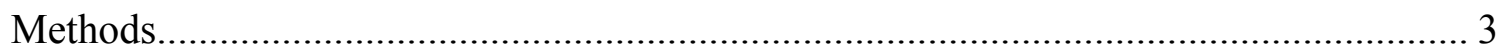

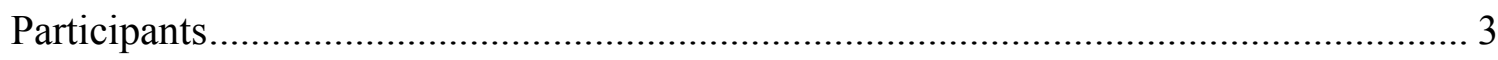

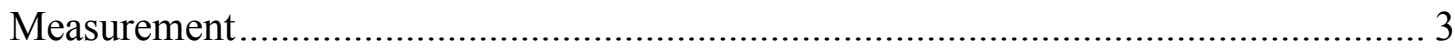

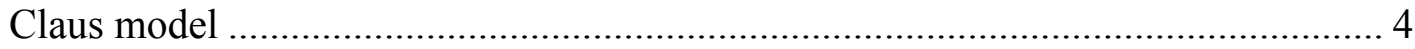

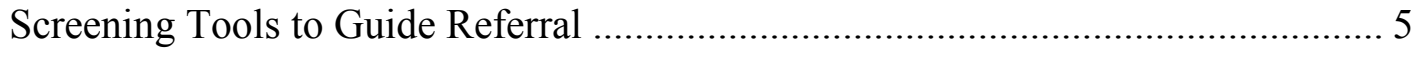

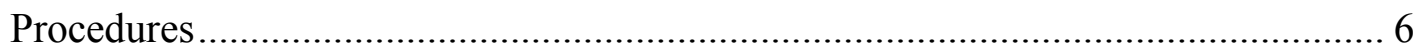

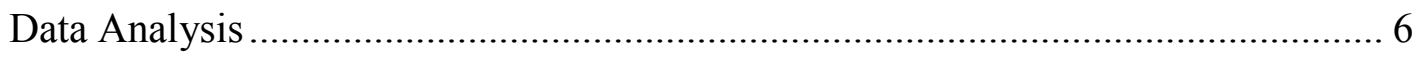

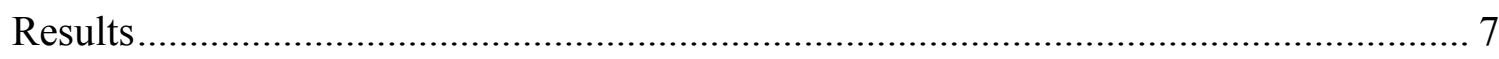

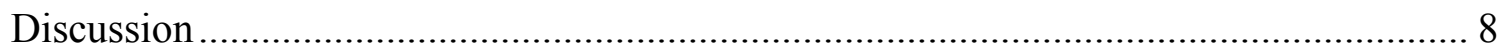

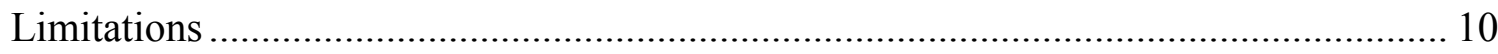

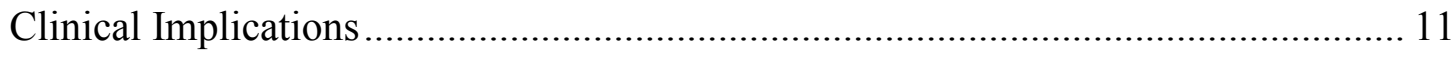

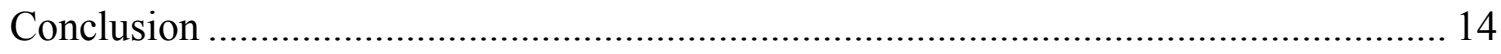




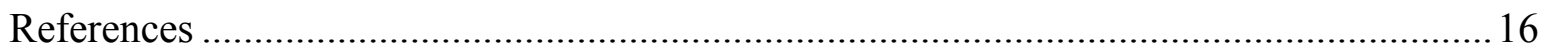




\section{LIST OF TABLES AND FIGURES}

Table 1 Description and Examples Risk Models vs. Screening Tools ............................ 21

Table 2 Description and Original Validation of Five Screening Tools......................... 29

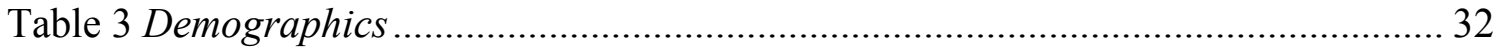

Table 4 Performance Indicators of Five Screening Tools

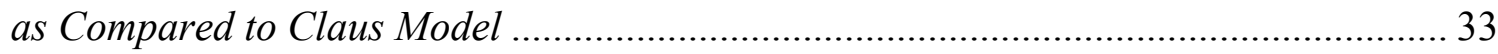

Figure 1 ROC Curves for Five Screening Tools to Guide Referral ................................. 34 


\author{
Breast Cancer Risk Assessment: \\ Evaluation of Screening Tools for Genetics Referral
}

\title{
Introduction
}

Recently, the United States Preventative Services Task Force (USPSTF) recommended that asymptomatic women who have not been diagnosed with breast cancer but who have concerning family history, including family members with breast, ovarian, tubal or peritoneal cancers, be assessed for cancer risk (Moyer, 2014). Although some clinicians may be skilled at performing in-depth risk assessments, others may opt to refer patients to genetics specialists for assessment. Therefore, to help clinicians identify patients who need referral, the USPSTF recommended primary care providers (PCPs) screen women by applying one of five screening tools (Moyer, 2014). The screening tools are designed to identify women who may have greater likelihood of developing breast cancer (Moyer, 2014). The USPSTF did not identify which tool is best for identifying patients needing referral (Moyer, 2014).

\section{Background}

The burden of disease caused by breast cancer is significant. Breast cancer is second only to skin cancer as the most common cancer in women (National Institute of Health (NIH), 2014). In 2016 in the United States (US), it is estimated more than 246,660 women will be newly diagnosed with breast cancer (NIH, 2016). The cost of breast cancer care for 2014 was estimated (in 2010 dollars) at 17.2 billion dollars in the US alone (NIH, 2014).

Guidelines for breast cancer screening vary based on individual risk. Because age of initiation, type, and frequency of screening varies, identifying women at elevated risk for breast cancer is essential to recommending appropriate screening. Women at increased risk of breast 
cancer may be offered earlier screenings, beginning at age 30 (or earlier, depending on family history), and/or screening that includes annual MRI in addition to annual mammograms (National Comprehensive Cancer Network, 2014; Saslow et al., 2007). Therefore, if individual risk is not calculated, women may not receive appropriate type and frequency of screening. Multiple risk assessment models are available to calculate lifetime breast cancer risk. Models may estimate breast cancer risk differently because they include different risk factors or weigh risk factors differently (Ozanne et al., 2013; NIH, 2016). Some risk models use only pedigree analysis, while other models include additional breast cancer risk factors such as early menarche or delayed childbearing. Only risk models that include extensive family history should be used for recommending annual screening breast MRI (National Comprehensive Cancer Network, 2015; Saslow et al., 2007; NIH, 2016). See Table 1 for risk assessment models that use extensive family history. For this reason, the Gail model (also known as the Breast Cancer Risk Assessment Tool) should not be used for determining need for screening MRI because it utilizes limited family history. (Saslow et al., 2007; NIH, 2016).

Use of risk assessment models can be complex. During an office visit, a PCP may not have the time to calculate breast cancer lifetime risk. Additionally, models available require specialized software and clinical time to enter data. Because PCPs may lack the time or expertise to calculate breast cancer lifetime risk (Hampel, Bennett, Buchanan, Pearlman \& Wiesner, 2015), the USPSTF has recommended five screening tools (Moyer, 2014) to identify patients who would benefit from referral to genetics professionals for in-depth risk assessment (Table 1). The USPSTF did not identify which tool is superior. Therefore, the purpose of this study was to assess the effectiveness of five tools recommended by the USPSTF in identifying women at 
elevated breast cancer risk. Use of these tools will then allow for appropriate genetic professional referral for risk assessment and, if appropriate, genetic mutation testing.

\section{Methods}

This descriptive study, using secondary analysis of data from previous research (Himes, Clayton, Donaldson, Ellington, Buys \& Kinney, 2015), evaluated the sensitivity, specificity, positive and negative predictive values, and receiver operating curves (ROC) for five screening tools. Data related to family history and risks for breast cancer were collected from 85 women through written surveys and telephone interviews. Institutional review board (IRB) approval was obtained for the original research and all participants gave informed consent (Himes et al., 2015). IRB approval was obtained separately for this study.

\section{Participants}

Participants included 85 women between the ages of 40 and 74. All participants were sisters or daughters of women who had a personal history of breast cancer and who had received uninformative negative genetic testing for BRCA1/2 gene mutations results from a board certified genetic counselor (Himes et al., 2015). Women were excluded if they had ever received breast cancer-related genetic testing, had received a prophylactic bilateral mastectomy or oophorectomy, had a personal history of any type of cancer other than non-melanoma skin cancer, and/or if they were of Ashkenazi Jewish descent, as the associated high-risk status with this ancestry necessitates special consideration in evaluating risk.

\section{Measurement}

Risk for breast cancer was assessed using the Claus model and five screening tools. The Claus model was used as the standard against which the five screening tools were evaluated. 
Screening tools were considered effective if they could identify women with Claus lifetime risk $>15 \%$ as needing referral to a genetics professional.

Claus model. Lifetime risk for breast cancer was calculated for 85-study participants using the Claus model (Claus, Risch \& Thompson, 1994) as part of the parent study (Himes et al., 2015). The Claus model is known to be moderate in its risk projections when compared to other risk assessment models (Ozanne et al., 2013). Additionally, both the NCCN (2015) and the ACS (Saslow et al., 2007) recommend the Claus model as appropriate for calculation of breast cancer lifetime risk for the purpose of ordering breast MRI.

The Claus model uses family history of first- and second-degree relatives with breast and ovarian cancer to estimate lifetime risk (up to age 79) of breast cancer (Amir, Freedman, Seruga \& Evans, 2010). The model includes information regarding age at disease onset and cancer history from both paternal and maternal family lines (Claus, Risch \& Thompson, 1994).

For the purpose of this study, women with a Claus breast cancer lifetime risk estimate of $>15 \%$ were considered to be at elevated risk - in other words, we counted screening tools as appropriately referring women if their lifetime risk calculation was $>15 \%$. Although $20 \%$ lifetime risk is the cut point at which several breast cancer-screening guidelines begin to recommend MRI, we selected $15 \%$ as a cut point for three reasons. First, over-referral is preferable to under-referral in a screening test (Warner, 2004). If 20\% were the threshold, fewer women would be identified as needing referral; however, some would be missed who could benefit from risk assessment. Second, women with risks calculated in the 15-20\% range may not actually be over-referred. In fact, American Cancer Society notes there is not sufficient evidence to recommend for or against screening breast MRI in women with lifetime risks 
between 15-20\% (American Cancer Society, 2015). Finally, the Claus model provides lower risk calculations than some other commonly used risk assessment models (Ozanne, 2013). Therefore, setting $>15 \%$ lifetime breast cancer risk as a cut point for referral recognizes that women not at elevated risk by the Claus model could be found to be at elevated risk by other models. Thus, a $15 \%$ cut point provides a reasonable buffer allowing for variance between risk assessment models (Ozanne, 2013; NIH, 2016).

Screening Tools to Guide Referral. The five tools in this study were recommended by the USPSTF as primary screening tools for patients who may be at increased risk for breast cancer due to family history (Moyer, 2014). The recommended tools include the Family History Assessment Tool (FHAT), also known as Ontario-Family History Assessment Tool (Gilpin, Carson \& Hunter, 2000). In this paper we will refer to this tool as Ontario-FHAT. The other four tools include the Manchester Scoring System (Evans et al, 2004); the Referral Screening Tool (RST) (Bellcross, Lemke, Pape, Tess \& Meisner, 2009); the Family History Screen-7 (FHS-7) (Ashton-Prolla et al., 2009); and the Pedigree Assessment Tool (PAT) (Hoskins, Zwaagstra \& Ranz, 2006).

All tools rely on patient knowledge of family history. Accurate recall and knowledge of cancer history to second or third degree relatives is key. Each tool can be completed with paper and pencil, and each takes 5 minutes or less to perform and score. An understanding of how to read pedigrees is essential. Clinicians should refer to specific instructions regarding how to score and the cut points for referral related to each tool as found in the original articles cited in Table 2.

Initially each tool was developed and validated in populations of differing risk (Table 2). Validation used in-depth risk assessment models and other methods of assessing breast cancer 
risk and/or likelihood of BRCA1/2 mutations rather than assessing their ability to predict breast cancer, which may occur many years into the future. See Table 2 for tool description, initial validation studies, validating population, and the gold standard measure against which it was assessed.

Procedures. For this secondary analysis, 85 de-identified participant pedigrees and Claus calculations from the parent study were accessed. Each pedigree was evaluated using all five screening tools recommended by the USPSTF. Scores derived from each instrument were compared to the participant's lifetime risk as previously calculated by the Claus model to determine each tool's ability to identify women with $>15 \%$ breast cancer lifetime risk. Women with $>15 \%$ risk as identified in the parent study formed the "elevated risk" group in this secondary analysis.

Data Analysis. Demographic data were described using means, standard deviations, and percents as obtained through SPSS software version 22. Sensitivity and specificity for each instrument were calculated to identify participants with Claus lifetime risk equal to or above $15 \%$. Sensitivity reflects the proportion of individuals with an elevated lifetime risk of developing breast cancer as identified by the Claus model who were correctly identified by the screening tool as needing a referral. Specificity reflects the proportion of individuals who did not have an elevated lifetime risk of developing breast cancer by the Claus model who were correctly identified by the tool as not needing referral.

Positive and negative predictive values were also calculated for each tool. A positive predictive value (PPV) represents the likelihood of having an elevated lifetime risk for breast cancer as identified by the Claus model when the screening tool also suggests additional referral 
is indicated. A negative predictive value (NPV) indicates the likelihood of not having an elevated lifetime risk for breast cancer as estimated by the Claus model when the screening tool suggests referral is not needed.

For each screening tool, a receiver operating characteristic (ROC) curve was generated with sensitivity along the $y$-axis and ( 1 minus specificity) along the $\mathrm{x}$-axis. The area under the ROC curve (AUC or C-statistic) is an indicator of the accuracy of a screening test. AUC values close to 1.0 represent high levels of both specificity and sensitivity, while values near 0.5 or below indicate lack of adequate specificity and sensitivity because no more cases would be identified as needing referral than by chance alone. An AUC of 0.7 to 0.8 represents good discriminatory accuracy (Amir, Freedman, Seruga \& Evans, 2010). The ROC curves and the statistics used for testing differences between ROC curves were estimated through logistic regression using SAS software version 9.4.

\section{Results}

Participants were primarily Caucasian and married; all were older than age 40 (Table 3). The Claus calculations identified 14 of $85(16 \%)$ women whose lifetime risk for breast cancer was $>15 \%$. Sensitivity, specificity, PPV, NPV, and AUC for each instrument are presented in Table 4. Sensitivity of the tools ranged from 57.1 to 100 , and specificity from 0 to 64.8 . Only the Ontario-FHAT and FHS-7 identified all 14 women with elevated risk as needing referral (Table 4). However, the FHS-7 tool flagged all 85 participants as needing referral to a genetic specialist for further analysis and risk assessment.

AUC values for the tools ranged from 0.65 to 0.72 (Figure 1). Chi-square analyses from the logistic regressions were run between each possible pair of tools. All $p$ values were $>0.05$, 
indicating that no tool performed significantly differently from another. Thus, AUC values were not helpful in discriminating between these tools.

The performance of the Ontario-FHAT was further evaluated by difference in age among women who were referred and found to be at elevated risk by the Claus model (true positives) vs. those who were referred and found to not have elevated risk (false positives or over-referrals). Women who were over-referred had a significantly higher average age (55 years old on average) than those who were appropriately referred ( 47 years old on average), $p=0.0098$. This indicates that if the Ontario-FHAT identifies an older woman as needing referral, she is ultimately less likely to be found to have elevated lifetime risk when a full risk assessment calculation is performed (via risk assessment model) when compared to a younger woman.

\section{Discussion}

Calculating lifetime breast cancer risk is a complex process, but critical for recommending appropriate screening in cases where family history is suspect. To help with decisions regarding which patients to refer, the USPSTF issued guidelines in 2014 intended to simplify the task (Moyer, 2014). However, the USPSTF did not give recommendations regarding which tool was superior, stating the evidence was insufficient to make a recommendation (Moyer, 2014). This study may be the first attempt to compare all five recommended screening tools to each other.

This study compared the performance of five USPSTF recommended screening tools to Claus model calculations of lifetime breast cancer risk for unaffected women, all of whom had a sister or mother affected by breast cancer. In assessing how each tool performed, of particular interest are 14 of the 85 women whose lifetime risk of developing breast cancer was calculated at 
$>15 \%$ per the Claus model. In evaluating tool performance, it was important that the tool had the ability of to identify all 14 women in the elevated risk category. Only two of the five tools met this standard; the Ontario-FHAT and the FHS-7, thus both had sensitivities of $100 \%$.

Although the FHS-7 had a sensitivity of $100 \%$, it recommended all 85 women be referred, giving it a specificity of $0 \%$, making it of little clinical utility. Since this tool refers any woman with a single first-degree relative with breast cancer, regardless of the relative's age at diagnosis, every woman in our study would have been referred to genetics professionals. A $100 \%$ referral rate is inefficient, and could overload the health care system. Harms of an overloaded health care system may include increased costs and wait times for services. Longer wait times may cause increased anxiety for patients.

In contrast, Ontario-FHAT proved more useful in this sample, identifying all 14 women in the elevated risk group as needing referral, giving it a sensitivity of $100 \%$. Its NPV was $100 \%$, meaning if it did not identify a patient as needing referral to a genetics professional, it is likely that person did not have an elevated lifetime risk of developing breast cancer (identified as $>$ $15 \%$ lifetime breast cancer risk by the Claus model).

The Ontario-FHAT did not outperform the other tools in all parameters. It had a comparatively low specificity (36.62\%). This is not unexpected, as sensitivity and specificity have an inverse relationship in a screening tool (Warner, 2004). The tradeoff between sensitivity and specificity is that to attain high sensitivity (identifying all members of the elevated risk group), the tool can be expected to over-refer, decreasing specificity. Conversely, if sensitivity is decreased, meaning some members from the elevated risk group are not identified, specificity can be expected to increase because over-referrals will decrease (Warner, 2004). Thus, because 
the goal of a screening tool is to identify all women at elevated risk, a higher sensitivity with the resulting lower specificity is desirable. Additionally, if a tool missed women at elevated risk, we not only miss an opportunity to screen not only the individual, but her family members as well, who may also be at additional risk.

The Ontario-FHAT had a low PPV at 23.73, although not the lowest. The PPV reflects the likelihood of a woman having elevated risk if the tool identified her as needing referral (Warner, 2004). For a screening tool, it is reasonable to refer some women at lower risk in preference to missing any women at elevated risk (Warner, 2004), so the low PPV is not undesirable. Additionally, for conditions with low prevalence (in this study, the prevalence of women with elevated risk was 16\%), lower PPVs are expected (Warner, 2004). Therefore, a low PPV is not necessarily a negative finding for the Ontario-FHAT.

Overall, the Ontario-FHAT outperformed the other tools. The combination of $100 \%$ sensitivity and 100\% NPV should reassure clinicians that when the Ontario-FHAT excludes an individual from referral the individual is unlikely to be at elevated risk.

\section{Limitations}

Study limitations include a racially homogenous sample, which may limit application to more diverse populations. In addition, written pedigrees previously collected were used to complete the screening tools rather than using face-to-face interviews. Therefore, at times assumptions about the family history were necessary which may have altered the data. For example, since we did not have the exact age of menopause for each relative affected with cancer, we counted cancers as occurring prior to menopause if they occurred at age 50 or younger because the average age of menopause is 51 in the United States (National Institutes of 
Health, 2015). These assumptions affected the scoring of the tools and could have varied had we conducted interviews in person.

Additionally, this study is limited by the age of participants. Future researchers should consider including participants as young as age 30 because screening guidelines (Saslow et al., 2007) for high-risk populations differ beginning at that age, and because lifetime risk is higher for younger individuals as they have more lifetime ahead.

\section{Clinical Implications}

As medicine moves into what has been termed the genomic era, clinicians must be prepared to care for the unique and changing attributes of individual patients. It is more effective to provide screening tests such as breast MRI for individuals at higher risk for disease than to screen entire populations. Assessing breast cancer risk in primary care settings is an ongoing process. Clinicians must be aware that a one-time family history assessment is not sufficient. Family history is dynamic (American College of Obstetricians and Gynecologists, 2015). As additional family members receive cancer diagnoses, an individual's risk estimate may rise. Similarly, an individual's risk level may decrease over time - as age increases, lifetime risk for cancer decreases because there is less time to develop illness.

In addition to changing individual risk, clinicians must also be aware of changes in breast cancer screening guidelines and risk assessment models. Recent research suggests it may be better to use 10-year risk estimates rather than lifetime risk scores to determine when breast MRI should be offered as part of an annual screening (Quante, Whittemore, Shriver, Hopper, Strauch \& Terry, 2015). 
Although the USPSTF screening tools are simpler to use than risk assessment models that calculate lifetime risk (Table 1), clinicians need to be aware of limitations of the tools. None of the screening tools account for age in assigning risk. Therefore, the tools may overestimate the need for referral in older women. Additionally, scoring the tools can be complex. Each tool is scored differently, and each varies in information considered. Clinicians should carefully supervise office staff if collection of data and scoring these tools is delegated, especially as staff learns to use and score the tools.

Clinicians may question if it is not more effective to order genetic tests for all patients with concerning family histories and/or those who are concerned about breast cancer risk. Certainly, the cost of genetic testing has dropped and inexpensive multi-gene panels are now available. However, patients and clinicians must understand that lack of a positive result does not rule out a hereditary basis for the cancer. Similarly, lack of a positive result does not mean risk is low. Only 5 to $10 \%$ of breast cancers are thought to be hereditary (caused by heritable genetic mutations) (NIH, 2016), and of those, only 10\% are caused by BRCA1/2 mutations, despite the fact that mutations in these genes are the most commonly identified cause of hereditary breast cancer $(\mathrm{NIH}, 2016)$. Indeed, in this study population all 85 women had a relative with an uninformative negative BRCA1/2 test, yet $16 \%$ were still at elevated risk for developing breast cancer based on family history alone. Thus, while genetic testing can be helpful, it is only part of the equation in caring for women with concerning family histories of breast cancer.

Caring for women at risk for breast cancer is a collaborative process, yet deciding which women to refer may be difficult for clinicians who are not specialists in cancer genetics (Hampel, 
Bennett, Buchanan, Pearlman, \& Wiesner, 2015). PCPs may choose to refer patients based on results of a brief screening tool such as those evaluated in this study, or after performing lifetime risk calculation using a risk assessment model described in Table 1. There are advantages and disadvantages to both options. PCP referral of individuals at elevated risk to genetics specialists is recommended by several organizations, including NCCN (2015), Saslow et al. (2007) and USPSTF (Moyer, 2014). Indeed, the USPSTF rates referring women suspected as being at elevated risk for breast cancer to genetic specialists as a "grade B" recommendation, meaning that it is a preventive service that should be covered by insurance with no cost or copay (Moyer, 2014).

An advantage of using the screening tools evaluated in this study is that they take relatively little time to use. In primary care, this may be a significant advantage, as limited time has been identified as a barrier to triggering genetic referrals (Hampel, Bennett, Buchanan, Pearlman \& Wiesner, 2015). A disadvantage to using these screening tools is that, as demonstrated in this study, they may over- or under-refer. Additionally, some of these tools were primarily designed to assess for the likelihood of carrying BRCA1/2 mutations. They do not screen for other rare cancer syndromes, also potential causes of breast cancer. Finally, none of the USPSTF recommended screening tools to guide referral are intended for the purpose of ordering breast MRI; therefore, none of them has clinical utility beyond referral.

Similarly, there are advantages and disadvantages for PCPs learning how to use risk assessment models. An advantage is that PCPs can order annual screening breast MRI based on lifetime risk calculations using one of the appropriate models (Table 1). However, PCPs who run their own lifetime risk calculations will still find occasion to refer patients. Indeed, the NCCN 
recommends that if a woman's risk is calculated to be $>20 \%$, she should be referred to a genetics specialist (National Comprehensive Care Network, 2015). Although using risk assessment models can be time-intensive, billing codes can be used to cover associated costs (Himes, Root, Gammon, Luthy, in review).

Regardless of the route PCPs take to refer women who may be at elevated risk to a genetic specialist, an advantage to referring patients is that genetic specialists have been trained to look for cancer syndromes beyond hereditary breast and ovarian cancer, caused by mutations in BRCA1/2 genes. Genetic specialists may be more prepared to diagnose rare genetic disease (Hampel, Bennett, Buchanan, Pearlman \& Wiesner, 2015).

Last, USPSTF strongly recommends that when genetic testing is performed, that pre- and post-test counseling with a genetics professional occur, as these professionals are most likely to be able to counsel regarding the legal, personal, and potential financial costs of genetic testing, as this is their area of expertise (Moyer, 2014). A similar caution comes from the American College of Medical Genetics and Genomics Practice Guidelines, who write: “. . genetic testing ... performed without such counseling by qualified clinicians has been associated with ... misinterpretation of genetic test results, inappropriate medical management, lack of informed decision making, violation of established ethical standards, adverse psychosocial outcomes, and costly, unnecessary genetic testing," (Hampel, Bennett, Buchanan, Pearlman, \& Wiesner, 2015, p.71).

\section{Conclusion}

The purpose of this study was to assess the effectiveness of five tools recommended by the USPSTF to identify women with concerning family histories of breast cancer who were 
appropriate for referral to genetics professionals for in-depth risk analysis. Although two models identified the 14 participants at elevated risk (i.e., identified by the Claus model as having a $>15 \%$ lifetime breast cancer risk), only the Ontario-FHAT had a combination of sensitivity of $100 \%$ and a negative predictive value of $100 \%$. Although the Ontario-FHAT had a lower specificity and PPV, these results are not unexpected in a screening tool where the goal is to identify all participants who are at elevated risk (high sensitivity), although necessarily some who are not at risk will also be referred (lower specificity). The AUC findings were compared and the five tools did not vary significantly from each other. Therefore, of the tools examined, and particularly for clinicians who lack the time or skill to utilize risk assessment models to calculate lifetime risk of breast cancer, this study suggests the Ontario-FHAT as the best among the tools examined for determining which patients should be referred to genetic specialists. 


\section{REFERENCES}

American Cancer Society (2015). American Cancer Society recommendations for early breast cancer detection in women without breast symptoms. Retrieved from http://www.cancer.org/cancer/breastcancer/moreinformation/breastcancerearlydetec tion/breast-cancer-early-detection-acs-recs

American College of Obstetricians and Gynecologists, Committee on Genetics (2015). Committee Opinion 634: Hereditary Cancer Syndromes and Risk Assessment. Obstetric Gynecology, (125). doi: 10.1097/01.AOG.0000466373.71146.51

Amir, E., Freedman, O. C., Seruga, B., \& Evans, D. G. (2010). Assessing women at high risk of breast cancer: A review of risk assessment models. Journal of the National Cancer Institute, 102(10). doi: 10.1093/jnci/djq088

Antoniou, A. C., Cunningham, A. P., Peto, J., Evans, D. G., Lalloo, F., Narod, S. A., . . \& \& Easton, D. F. (2008). The BOADICEA model of genetic susceptibility to breast and ovarian cancers: updates and extensions. British Journal Of Cancer. 98(8). doi: 10. 1038/sj.bjc.6604305

Antoniou, A. C., Hardy, R., Walker, L., Evans, D. G., Shenton, A., Eeles, R., . . \& \& Pharoah, P.D.P. (2008). Predicting the likelihood of carrying a BRCA1 or BRCA2 mutation: Validation of BOADICEA, BRCAPRO, IBIS, Myriad and the Manchester scoring system using data from UK genetics clinics. Journal of Medical Genetics (45). doi: 10.1136/jmg. 2007.05655 
Ashton-Prolla P., Giacomazzi J., Schmidt A.V., Roth F. L., Palmero E. I., Kalakun, L., . . . \& Camey, S. A. (2009). Development and validation of a simple questionnaire for the identification of hereditary breast cancer in primary care. BioMed Central Cancer, (9). doi: $10.1186 / 1471-2407 / 9 / 283$

Bellcross C., Lemke A., Pape L., Tess A., \& Meisner L. (2009). Evaluation of a breast/ovarian cancer genetics referral screening tool in a mammography population. Genetic Medicine, (11), 11. doi: 10.1097/ GIM. 0b013e3181b9b04a

Berry, D. A., Iversen, E. S., Jr., Gudbjartsson, D. F., Hiller, E. H., Garber, J. E., . . . \& Parmigiani, G. (2002). BRCAPRO validation, sensitivity of genetic testing of BRCA1/BRCA2, and prevalence of other breast cancer susceptibility genes. Journal Of Clinical Oncology: Official Journal Of The American Society Of Clinical Oncology. 20(11). doi: 10.1200/ JCO.2002.05.121JCO

Claus, E. B., Risch, N., \& Thompson, W. D. (1994). Autosomal dominant inheritance of early-onset breast cancer: Implications for risk prediction. Cancer, 73(3). doi: 10.1002/1097-0142(19940201)73:3<643::AID-CNCR2820730323>3 $.0 . \mathrm{CO} ; 2-5$

Evans, D., Eccles, D, Rahman, N., Young, K., Bulman, M., Amir, E., . . . \& Lalloo, F. (2004). A new scoring system for the chances of identifying a BRCA1/2 mutation outperforms existing models including BRCAPRO. Journal of Medical Genetics, (41). doi: 10.1136/ jmg.2003.017996

Gail, M. H., Brinton, L. A., Byar, D. P., Corle, D.K., Green, S.B., Schairer, C. \& Mulvihill, J.J. (1989). Projecting individualized probabilities of developing 
breast cancer for white females who are being examined annually. Journal of the National Cancer Institute, (81)24. doi: 10.1093/jnci/82.10.880

Gilpin C. A., Carson N. \& Hunter A. G. (2000). A preliminary validation of a family history assessment form to select women at risk for breast or ovarian cancer for referral to a genetics center. Clinical Genetics, (58). doi: 10.1034/j.1399-0004. 2000.580408.x

Hampel, H., Bennett, R. L., Buchanan, A., Pearlman, R. \& Wiesner, G. L. (2015). A practice guideline from the American College of Medical Genetics and Genomics and the National Society of Genetic Counselors: Referral indications for cancer predisposition assessment. Genetics in Medicine, (17)1. doi: 10.1038/ gim.2014. 147

Himes, D. O., Clayton, M.F., Donaldson, G.W., Ellington, L., Buys, S.S., \& Kinney, A.Y. (2016). Breast cancer risk perceptions among relatives of women with uninformative negative $B R C A 1 / 2$ test results: The moderating effect of the amount of shared information. Journal of Genetic Counseling, (25)2. doi: 10. 1007/s10897-015-9866-0

Himes, D. O., Root, A. E., Gammon, A. \& Luthy, K. E., Breast cancer risk assessment: Calculating lifetime risk using Tyrer-Cuzick model (in review).

Hoskins, K. F., Zwaagstra, A., \& Ranz, M. (2006). Validation of a tool for identifying women at high risk for hereditary breast cancer in population-based screening. Cancer, 107(8). doi: 10.1002/cncr.22202

Moyer, V. (2014). Risk assessment, genetic counseling, and genetic testing for 
BRCA-related cancer in women: U.S. preventive services task force recommendations statement. Annals of Internal Medicine, (160)4. doi: 10.7326/ M13-2747

National Comprehensive Care Network (NCCN). (2015). Clinical practice guidelines in oncology - breast cancer screening and diagnosis. Retrieved from https://www. nccn.org/professionals/physician_gls/pdf/breast-screening.pdf

Ozanne, E. M., Drohan, B., Bosinoff, P., Semine, A., Jellinek, M., Cronin, ... \& Hughes, K.S. (2013). Which risk model to use? Clinical implications of the ACS MRI screening guidelines. Cancer EpidemiologyBiomarkers \& Prevention, 22(1). doi: 10.1158/1055-9965.EPI-12-0570

Quante, A.S., Whittemore, A.S., Shriver, T., Hopper, J. L., Strauch, K. \& Terry, M. B. (2015). Practical problems with clinical guidelines for breast cancer prevention based on remaining lifetime risk. Journal of the National Cancer Institute. 107(7). doi: 10.1093/jnci/djv124

Saslow, D., Boetes, C., Burke, W., Harms, S., Leach, M. O., Lehman, C. D., . . . \& Russell, C. A. and for the American Cancer Society Breast Cancer Advisory Group. (2007). American Cancer Society Guidelines for Breast Screening with MRI as an Adjunct to Mammography. CA: A Cancer Journal for Clinicians, 57(2). doi: 10.3322/canjclin.57.2.75

Tyrer, J., Duffy, S. W. \& Cuzick, J. (2004). A breast cancer prediction model incorporating familial and personal risk factors. Statistics In Medicine, 23(7). doi: 10.1002/sim. 1913 
U.S. Department of Health and Human Services, National Institutes of Health. Genetics Home Reference. (2016). Breast Cancer. Retrieved from https://ghr.nlm.nih.gov/ condition/breast-cancer\#diagnosis

U.S. Department of Health and Human Services, National Institutes of Health. National Cancer Institute. (2016). Genetics of Breast and Gynecologic Cancers - Health Professional Version. Retrieved from http://www.cancer.gov/types/breast/hp/breastovarian-genetics-pdq\#link/_2824_toc

U.S. Department of Health and Human Services, National Institutes of Health. National Cancer Institute. (2014). A snapshot of breast cancer - Incidence and mortality. Retrieved from http://www.cancer.gov/research/progress/snapshots/breast

U.S. Department of Health and Human Services, National Institutes of Health. National Institute on Aging. (2015). Menopause. Retrieved from https://www.nia.nih.gov /health/publication/menopause

Warner, James. (2004). Clinician's guide to evaluating diagnostic and screening tests in psychiatry. Advances in Psychiatric Treatment, 10(6), 446-454. doi: 10.1192 /apt.10.6.446 
Table 1

Description and Examples Risk Models vs. Screening Tools

\begin{tabular}{|c|c|}
\hline Description & Examples \\
\hline $\begin{array}{l}\text { Risk Assessment Models**: } \\
\text { Used as part of an in-depth risk assessment for hereditary } \\
\text { cancer syndromes and/or likelihood of carrying BRCA1/2 } \\
\text { mutations. Requires specialized computer software. } \\
\text { Models take extensive family history into account. Used to } \\
\text { calculate risk for breast cancer (as \% in number of years or } \\
\text { lifetime). Appropriate to use for purpose of determining } \\
\text { who to offer breast MRI as part of annual screening. }\end{array}$ & $\begin{array}{l}\text { BRCAPRO }^{1} \\
\text { Claus }^{2} \\
\text { Tyrer-Cuzick }^{3} \\
\text { BOADICEA }^{4}\end{array}$ \\
\hline $\begin{array}{l}\text { Screening Tools to Guide Referral: } \\
\text { Designed to assist primary care providers identify women } \\
\text { who would benefit from referral to genetics specialists for } \\
\text { in-depth risk assessment. Paper/ pencil instruments that } \\
\text { require just a few minutes of time. These tools provide a } \\
\text { general assessment of breast cancer risk and/or likelihood } \\
\text { of carrying BRCA1/2 mutation. These are NOT to be used } \\
\text { for the purpose of determining who to offer breast MRI as } \\
\text { part of annual screening. }\end{array}$ & $\begin{array}{l}\text { Ontario-FHAT } \\
\text { Manchester }^{6} \\
\text { RST }^{7} \\
\text { FHS-7 }^{8} \\
\text { PAT }^{9}\end{array}$ \\
\hline
\end{tabular}

**Note, although the Gail model (Breast Cancer Risk Assessment Tool - BCRAT) will also calculate lifetime and 5 -year risk, it is not recommended for use in determining who should be offered screening breast MRI because it does not take extensive family history into account.

1 (Berry et al., 2002); ${ }^{2}$ (Claus, Risch \& Thompson, 1994); ${ }^{3}$ (Tyrer, Duffy \& Cuzick, 2004); ${ }^{4}$ (Antoniou et al., 2008); ${ }^{5}$ Family History Assessment Tool (FHAT), also called Ontario-Family History Assessment Tool (OntarioFHAT), (Gilpin, Carson \& Hunter, 2000); ${ }^{6}$ Manchester Scoring System (Evans et al, 2004);

${ }^{7}$ Referral Screening Tool (Bellcross, Lemke, Pape, Tess \& Meisner, 2009); ${ }^{8}$ Family History Screen-7 (AshtonProlla et al., 2009); ${ }^{9}$ Pedigree Assessment Tool (Hoskins, Zwaagstra \& Ranz, 2006). 
Table 2

Description and Original Validation of Five Screening Tools

\begin{tabular}{|c|c|c|}
\hline Tool Name \& Description & \multicolumn{2}{|c|}{ Original Validation Studies } \\
\hline $\begin{array}{l}\text { FHAT-Ontario } \\
\text { - No. of questions: } 17 \\
\text { - Referral cut point: } \geq 10 \\
\text { - May use in Ashkenazi Jewish population? Yes } \\
\text { - Weighted questions? No } \\
\text { Note: maternal and paternal lines scored separately, } \\
\text { highest number used to estimate risk }\end{array}$ & $\begin{array}{l}\text { Sample: } \\
\text { - Purposive sample, } 184 \text { participants (all with } \\
\text { approximately doubled lifetime risk due to family } \\
\text { history) recruited through Ontario cancer registry, } \\
\text { physician referrals, and a NIH local research study. } \\
\text { Evaluated: } \\
\text { - Tool's ability to identify women who had a } 22 \% \\
\text { lifetime risk for breast cancer in either the Claus model } \\
\text { or BRCAPRO. }\end{array}$ & $\begin{array}{l}\text { Results: Compared to Claus model } \\
\text { - Sensitivity: } 0.74 \\
\text { - Specificity: } 0.54 \\
\text { - } \mathrm{PPV}^{1}: 0.28 \\
\text { - } \mathrm{NPV}^{2} 0.90 \\
\text { - } \mathrm{AUC}^{3}: \text { Not done. } \\
\text { (See author's original work for other } \\
\text { comparisons) }\end{array}$ \\
\hline $\begin{array}{l}\text { Manchester } \\
\text { - No. of questions: } 12 \\
\text { - Referral cut point ( } 2 \text { ways to score): } \geq 10 \text { or } 15 \\
\text { - May use in Ashkenazi Jewish population? No } \\
\text { - Weighted questions? Yes } \\
\text { Note: Screens for both } B R C A 1 \text { and } B R C A 2 \\
\text { mutations individually and together }\end{array}$ & $\begin{array}{l}\text { Sample: } \\
\text { - Convenience sample of } 422 \text { patients with a personal or } \\
\text { family history of breast or ovarian cancer who presented } \\
\text { to cancer genetics clinics b } \\
\text { - Those of Ashkenazi heritage excluded from sample as } \\
\text { high risk } \\
\text { Evaluated: } \\
\text { - Tool's ability to identify women who had a } \geq 10 \% \\
\text { likelihood of carrying a BRCA1/2 gene mutation as } \\
\text { defined by several models/tools (BRCAPRO, Couch, } \\
\text { Frank1, Frank 2) }\end{array}$ & $\begin{array}{l}\text { Results: Compared to BRCAPRO } \\
\text { - Sensitivity: } 61 \% \\
\text { - Specificity: } 44 \% \\
\text { - AUC }{ }^{3} 0.60 \\
\text { (See author's original work for other } \\
\text { comparisons) }\end{array}$ \\
\hline
\end{tabular}




\begin{tabular}{l} 
Tool Name \& Description \\
\hline RST $^{\mathrm{c}}$ \\
- No. of questions: 18 \\
- Referral cut point: $\geq 2$ \\
- May use in Ashkenazi Jewish population? Yes \\
- Weighted questions? Yes
\end{tabular}

- Weighted questions? Yes

- No. of questions: 7

- Referral cut point: $\geq 1$

- May use in Ashkenazi Jewish population? Yes

- Weighted questions? No

Original Validation Studies

Sample:

Results: Compared to BOADICEA

Convenience sample of 2464 women undergoing screening mammography.

- Sensitivity: 0.91

- Specificity: 0.76

- $\mathrm{AUC}^{3} 0.84$

Evaluated:

- Tool's ability to identify women with a $\geq 10 \%$ likelihood of carrying $B R C A 1 / 2$ mutation as defined by several models/tools (BOADICEA, BRCAPRO, Myriad

(See author's original work for other comparisons)

II) or an Ontario-FHAT score $\geq 10$

FHS- $7^{\mathrm{d}}$

\section{Sample:}

- Convenience sample of 1795 women to whom FHS-7 was applied during routine visits to primary care in southern Brazil.

\section{Evaluated:}

- Tool's ability to identify women with family history consistent with high-risk hereditary breast cancer syndromes. This included several hereditary breast cancer syndromes.

\section{Sample:}

\section{PAT $^{\mathrm{e}}$}

- No. of questions: 5

- Referral cut point: $\geq 8$

- May use in Ashkenazi Jewish population? Yes

- Weighted questions? Yes

Note: maternal and paternal lines scored separately, highest number used to estimate risk
- Convenience sample of 3906 women presenting at community hospital for screening mammography.

\section{Evaluated:}

- Tool's ability to categorize women as "high $B R C A$ probability" vs. "low $B R C A$ probability" as defined by criteria developed by authors.

- $\mathrm{AUC}^{3}$ for tool's ability to identify women with $>10 \%$ risk of carrying BRCA1/2 mutations as defined by the Frank model.
Results: Compared to women who

meet clinical criteria for hereditary breast cancer syndromes (overall).

- Sensitivity: 0.88

- Specificity: 0.56

- $\mathrm{AUC}^{3} 0.83$

(See author's original work for other comparisons)

\section{Results: Compared to criteria}

developed by authors

- Sensitivity: $100 \%$

- Specificity: 93\%

- Compared to Frank model

- $\mathrm{AUC}^{3} 0.96$

(See author's original work for other comparisons) 
Tool Name \& Description

Original Validation Studies

${ }^{\mathrm{a}}$ Family History Assessment Tool, also called Ontario Family History Assessment Tool (Gilpin, Carson \& Hunter, 2000).

${ }^{b}$ Manchester Scoring System (Evans et al, 2004).

${ }^{c}$ Referral Screening Tool (Bellcross, Lemke, Pape, Tess \& Meisner, 2009).

${ }^{\mathrm{d}}$ Family History Screen-7 (Ashton-Prolla et al., 2009).

e Pedigree Assessment Tool (Hoskins, Zwaagstra \& Ranz, 2006).

${ }^{1} \mathrm{PPV}=$ Positive predictive value $;{ }^{2} \mathrm{NPV}=$ negative predictive value; ${ }^{3} \mathrm{AUC}=$ Area under curve. 
Table 3

Demographics

\begin{tabular}{|c|c|c|c|}
\hline \multirow[t]{2}{*}{ Category } & & \multicolumn{2}{|c|}{ Participants } \\
\hline & & $n$ & $(\%)$ \\
\hline \multicolumn{4}{|l|}{$\overline{\text { Age }}$} \\
\hline & $40-49$ & 37 & $(44.0)$ \\
\hline & $50-59$ & 28 & $(33.3)$ \\
\hline & $60-69$ & 14 & $(16.7)$ \\
\hline & $70-74$ & 5 & $(6.0)$ \\
\hline \multicolumn{4}{|l|}{$\begin{array}{l}\text { Race/ } \\
\text { ethnicity }\end{array}$} \\
\hline & Non-Hispanic White & 83 & $(98.8)$ \\
\hline & Asian & 1 & $(1.2)$ \\
\hline \multicolumn{4}{|l|}{ Education } \\
\hline & High school/ GED & 13 & $(15.5)$ \\
\hline & Some college & 15 & $(17.9)$ \\
\hline & Vocational & 8 & $(9.5)$ \\
\hline & 2 year college & 9 & $(10.7)$ \\
\hline & 4 year college & 28 & $(33.3)$ \\
\hline & Master's degree & 11 & (13.1) \\
\hline \multicolumn{4}{|c|}{ Marital status } \\
\hline & Married & 67 & $(79.8)$ \\
\hline & $\begin{array}{l}\text { Member unmarried } \\
\text { couple }\end{array}$ & 1 & $(1.2)$ \\
\hline & Separated & 3 & (3.6) \\
\hline & Divorced & 9 & $(10.7)$ \\
\hline & Widowed & 2 & $(2.4)$ \\
\hline & Never married & 2 & $(2.4)$ \\
\hline Total & & 84 & $(100.0)$ \\
\hline
\end{tabular}


BREAST CANCER RISK ASSESSMENT

33

Table 4

Performance Indicators of Five Screening Tools as Compared to Claus Model

\begin{tabular}{|c|c|c|c|c|c|c|c|}
\hline Tool & $\begin{array}{c}\text { Sensitivity } \\
(\%)\end{array}$ & $\begin{array}{c}\text { Specificity } \\
(\%)\end{array}$ & $\mathrm{PPV}^{1}$ & $\mathrm{NPV}^{2}$ & $\begin{array}{c}\mathrm{AUC}^{3} \\
{[95 \% \mathrm{CI}]}\end{array}$ & $\begin{array}{c}\text { Number of } \\
\text { elevated risk } \\
\text { women } \\
\text { referred }\end{array}$ & $\begin{array}{c}\text { Number of } \\
\text { non-elevated } \\
\text { risk women } \\
\text { referred }\end{array}$ \\
\hline FHAT-Ontario $^{a}$ & 100 & 36.62 & 23.73 & 100 & $\begin{array}{c}0.72 \\
{[0.61-0.82]}\end{array}$ & $14 / 14$ & $45 / 71$ \\
\hline Manchester ${ }^{\mathrm{b}}$ & 57.14 & 64.79 & 24.24 & 88.46 & $\begin{array}{c}0.65 \\
{[0.53-0.78]}\end{array}$ & $8 / 14$ & $25 / 71$ \\
\hline $\mathrm{RST}^{\mathrm{c}}$ & 78.57 & 46.48 & 22.45 & 91.67 & $\begin{array}{c}0.69 \\
{[0.55-0.82]}\end{array}$ & $11 / 14$ & $38 / 71$ \\
\hline $\mathrm{PAT}^{\mathrm{d}}$ & 78.57 & 67.75 & 26.83 & 93.18 & $\begin{array}{c}0.63 \\
{[0.50-0.75]}\end{array}$ & $11 / 14$ & $30 / 71$ \\
\hline FHS- $7^{\mathrm{e}}$ & 100 & 0 & 16.47 & 0 & $\begin{array}{c}0.67 \\
{[0.57-0.77]}\end{array}$ & $14 / 14$ & $71 / 71$ \\
\hline
\end{tabular}

${ }^{\mathrm{a}}$ Family History Assessment Tool, also called Ontario Family History Assessment Tool (Gilpin, Carson \& Hunter, 2000). ${ }^{\mathrm{b}}$ Manchester Scoring System (Evans et al, 2004). ${ }^{\mathrm{c}}$ Referral Screening Tool (Bellcross, Lemke, Pape, Tess \& Meisner, 2009). ${ }^{\mathrm{d}}$ Family History Screen-7 (Ashton-Prolla et al., 2009). ${ }^{\mathrm{e}}$ Pedigree Assessment Tool (Hoskins, Zwaagstra \& Ranz, 2006). ${ }^{1} \mathrm{PPV}=$ Positive predictive value; ${ }^{2} \mathrm{NPV}=$ negative predictive value; ${ }^{3} \mathrm{AUC}=$ Area under curve 


\section{BREAST CANCER RISK ASSESSMENT}

Figure 1

ROC Curves for Five Screening Tools to Guide Referral

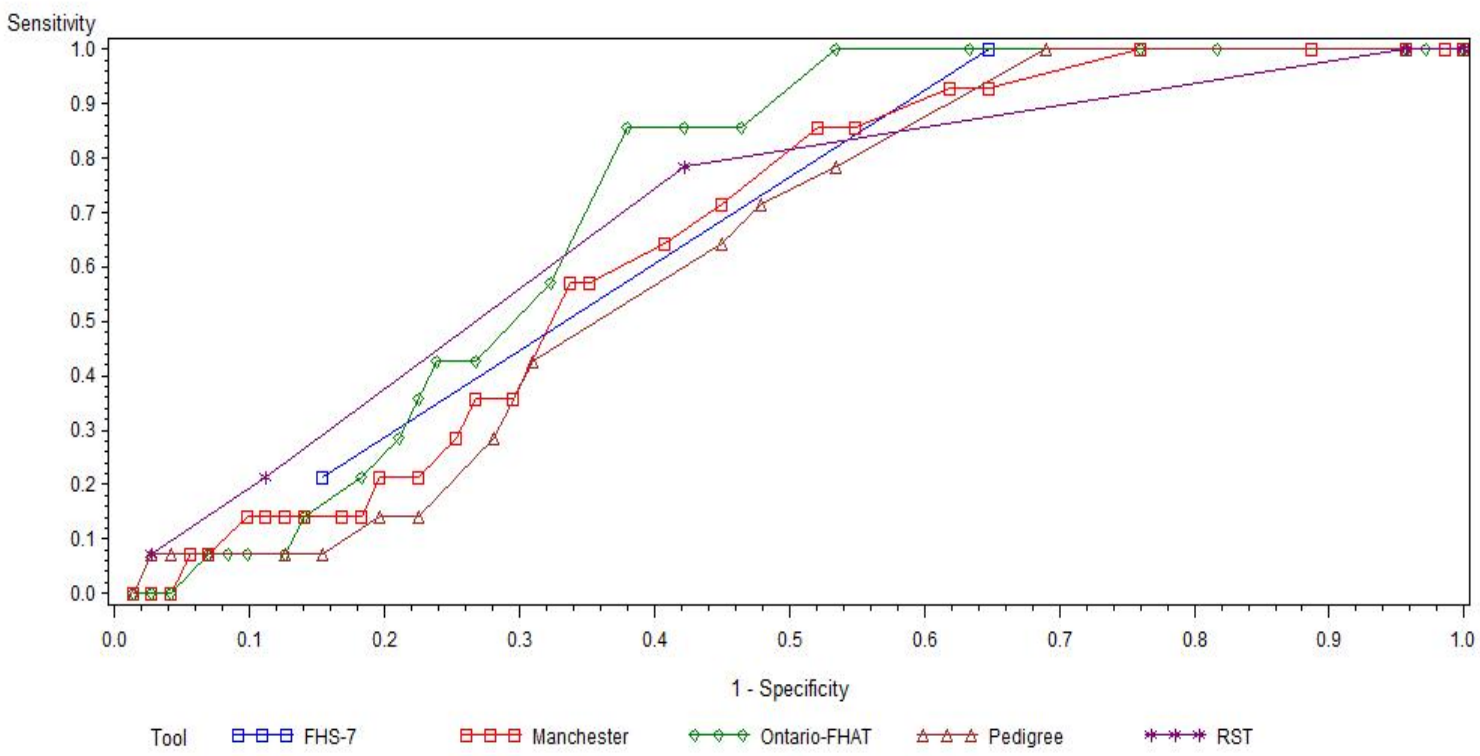

